\title{
Level and Value of Interleukin-18 in Patients With Acute Myocardial Infarction Undergoing Primary Coronary Angioplasty
}

\author{
Ali A. Youssef, MD; Li-Teh Chang, PhD*; Chi-Ling Hang, MD**; \\ Chiung-Jen $\mathrm{Wu}, \mathrm{MD}^{* *}$; Cheng-I Cheng, MD**; Cheng-Hsu Yang, MD**; \\ Jiunn-Jye Sheu, MD ${ }^{\dagger}$; Han-Tan Chai, MD**; Sarah Chua, MD**; \\ Kuo-Ho Yeh, MD**; Hon-Kan Yip, MD**
}

\begin{abstract}
Background The prognostic value of interleukin (IL)-18 in patients with ST-segment elevation acute myocardial infarction (STEMI) is currently unclear. Thus, the purpose of this study was to test whether the circulating IL-18 level can predict prognosis in patients with STEMI undergoing primary percutaneous coronary intervention (PCI).

Methods and Results A prospective cohort study was conducted with 267 consecutive patients with STEMI of onset $<12 \mathrm{~h}$ who were undergoing primary PCI. Blood samples for plasma IL-18 level were collected in the catheterization laboratory following vascular puncture. The plasma IL-18 level was also evaluated in 25 healthy and 30 at-risk control subjects. The plasma level of IL-18 was significantly higher in acute myocardial infarction (AMI) patients than in both groups of control subjects (all $\mathrm{p}<0.0001$ ). Patients with high plasma IL-18 level $(\geq 560 \mathrm{pg} / \mathrm{ml}$ ) had significantly higher peak creatine kinase-MB levels, higher incidence of cardiogenic shock upon presentation, significantly lower left ventricular ejection fraction (LVEF), lower successful reperfusion and significantly higher incidence of 30-day composite major adverse clinical events (MACE) (advanced congestive heart failure $\geq$ class 3 or 30 -day mortality) than those patients with low plasma IL-18 level $(<560 \mathrm{pg} / \mathrm{ml}$ ) (all $\mathrm{p}<0.0001)$. Multiple stepwise logistic regression analysis demonstrated that high plasma IL-18 level $(\geq 560 \mathrm{pg} / \mathrm{ml})$ along with low LVEF $(<50 \%)$ and cardiogenic shock were the most independent predictors of 30day MACE $(\mathrm{p}<0.0001)$.

Conclusions In patients with STEMI, plasma IL-18 level is a major independent inflammatory predictor of 30day MACE. Evaluation of circulating IL-18 might improve the prediction of unfavorable clinical outcomes following AMI. (Circ J 2007; 71: 703-708)
\end{abstract}

Key Words: Acute myocardial infarction; Interleukin-18; Major adverse clinical outcomes

A therosclerosis is intimately associated with an inflammatory process ${ }^{1,2}$ and there is now plenty of data to demonstrate that vulnerable plaque is characterized by accumulation of inflammatory cells, particularly macrophages and $\mathrm{T}$ lymphocytes? ${ }^{2-4}$ These inflammatory cells of unstable plaques produce high levels of the inflammatory cytokines that are responsible for the detrimental effects of plaque composition (ie, decreased number of smooth muscle cells and amount of collagen), $, 3,5-7$ which subsequently lead to plaque rupture and acute coronary syndrome (ACS) ${ }^{2-4,8}$ Much of the evidences has also demonstrated that acute myocardial infarction (AMI) is associated with inflammation ${ }^{2,8-11}$ and that inflammation

(Received October 26, 2006; revised manuscript received December 25, 2006; accepted February 2, 2007)

Cardiology Department, Suez Canal University Hospital, Ismailia, Egypt, *Division of Basic Medical Science, Department of Nursing, Meiho Institute of Technology, Ping Tung, **Division of Cardiology and Department of Cardiovascular Surgery, Chang Gung Memorial Hospital-Kaohsiung Medical Center, Chang Gung University Collage of Medicine, Kaohsiung, Taiwan, ROC

Mailing address: Hon-Kan Yip, MD, Division of Cardiology, Department of Internal Medicine, Chang Gung Memorial Hospital, Kaohsiung, 123 Ta Pei Road, Niao Sung Hsiang, Kaohsiung Hsien, 83301

Taiwan, ROC. E-mail: tang@adm.cgmh.org.tw plays an essential role in myocardial necrosis ${ }^{12}$ and microvascular reperfusion injury ${ }^{9}$ in patients with ACS. Therefore, the rationale is that inflammatory mechanisms have an important role in the occurrence of $\mathrm{AMI}^{2,8-14}$ and that inflammatory cytokines could be useful as predictors of clinical outcomes following AMI. Although investigators are likely to address whether some inflammatory markers are superior to others or add some complementary findings by simultaneous determination, comparative data forsingle inflammatory predictors are sparse! 13,14

Interleukin (IL)-18 is a member of the IL-1 family of cytokines and is processed, like IL- $\mathbb{\beta}$, by caspase 1 15-16 $^{15}$ Originally, IL-18 was identified as an interferon- $y$-inducing factor ${ }^{17}$ stimulating interferon- $\gamma$-induction in $\mathrm{T}$ lymphocytes and natural killer cells, which have been ascribed a key role in atherosclerotic plaque rupture6,18,19 There is increasing data to demonstrate that IL-18 is a pleiotropic proinflammatory cytokine ${ }^{20}$ acting in both acquired and innate immunity, and plays a crucial role in the inflammatory cascade ${ }^{21}$ Recent evidence from experimental studies has demonstrated that IL-18 is intimately related to atherosclerotic plaque propagation and instability9,22,23 Additionally, IL-18 has been found to be independently predictive of future coronary events in both coronary disease and healthy subjects ${ }^{14,24}$ Although 1 previous small study dem- 
Table 1 Baseline Characteristics of Study Patients, and the At-Risk Control and Normal Control Subjects

\begin{tabular}{|c|c|c|c|c|}
\hline & $\begin{array}{l}\text { Study patients } \\
\quad(n=267)\end{array}$ & $\begin{array}{l}\text { At-risk control } \\
\quad(n=30)\end{array}$ & $\begin{array}{c}\text { Normal control } \\
\quad(n=25)\end{array}$ & $p$ value $e^{\frac{t}{t}}$ \\
\hline Age (years) (mean $\pm S D)$ & $60.3 \pm 12.3$ & $61.1 \pm 10.3$ & $60.6 \pm 12.5$ & 0.684 \\
\hline Male gender & $80.5 \%(215)$ & $76.7 \%(23)$ & $80.0 \%(20)$ & 0.841 \\
\hline Hypertension & $53.6 \%(143)$ & $50.0 \%(15)$ & - & 0.711 \\
\hline Diabetes mellitus & $31.8 \%(85)$ & $36.7 \%(11)$ & - & 0.592 \\
\hline Current smoking & $42.7 \%(114)$ & $46.7 \%(14)$ & - & 0.677 \\
\hline Hypercholesterolemia & $46.1 \%(123)$ & $43.3 \%(13)$ & - & 0.776 \\
\hline Previous stroke & $7.5 \%(20)$ & - & & \\
\hline Previous myocardial infarction & $7.2 \%(19)$ & - & & \\
\hline \multicolumn{5}{|l|}{ Inflammatory biomarkers* } \\
\hline$h s-C R P(m g / L)$ & $9.0 \pm 20.4^{a}$ & $1.5 \pm 0.7^{b}$ & $1.1 \pm 0.6^{c}$ & $<0.0001$ \\
\hline WBC counts $\left(\times 10^{3} / \mathrm{ml}\right)$ & $10.2 \pm 3.4^{a}$ & $6.2 \pm 1.3^{b}$ & $6.3 \pm 1.3^{b}$ & $<0.0001$ \\
\hline$I L-18(\mathrm{pg} / \mathrm{ml})$ & $498 \pm 511^{a}$ & $155 \pm 99 b$ & $101 \pm 72^{c}$ & $<0.0001$ \\
\hline Successful reperfusion ${ }^{\dagger}$ & $90.3 \%(241)$ & - & - & \\
\hline
\end{tabular}

Data are mean value $\pm S D$ or $\%$ (no.) of patients.

hs-CRP, high-sensitivity $C$-reactive protein; $W B C$, white blood cell; $I L$, interleukin.

$* a, b, c$ indicate significant difference (at 0.05 level) by Wilcoxon's rank sum test with Bonferroni's correction.

Infarct-related artery achieved normal coronary blood flow.

Continuous data analyzed by Kruskal-Wallis test, and categorical data analyzed by chi-square test.

onstrated that IL-18 was markedly increased and correlated with myocardial injury in patients following $\mathrm{AMI}^{25}$ the prognostic value of IL-18 in the clinical setting of AMI is currently unknown. Thus, the purpose of this study was to evaluate the circulating level of IL-18 and its relationship with prognostic outcomes in patients with AMI undergoing primary percutaneous coronary intervention (PCI).

\section{Methods}

\section{Patient Population and Inclusion Criteria}

All patients with AMI were considered eligible for primary PCI. For the purpose of this study, blood samples for plasma IL-18 levels were drawn into EDTA tubes in the cardiac catheterization room following vascular puncture. To circumvent other potential influences on the circulating level of IL-18, we excluded patients with a history of recent surgery or trauma during the preceding 2 months, renal insufficiency (creatinine $>1.5 \mathrm{mg} / \mathrm{dl}$ ), malignancy, febrile disorders, acute or chronic inflammatory disease at study enrollment, autoimmune diseases with or without immunosuppressive therapy, or a prior myocardial infarction (MI) <3 months. Thus, between November 2002 and May 2004, 267 consecutive patients of any age, who presented with AMI $<12 \mathrm{~h}$ duration and underwent primary PCI were prospectively investigated and recruited.

Thirty subjects matched for age, gender, hypertension, diabetes mellitus, current smoking and hypercholesterolemia were assigned as the at-risk control group and an additional 25 age- and gender-matched healthy volunteers were assigned as the healthy control group. Informed consent was obtained from each study subject. The Institutional Review Committee on Human Research approved the study protocol.

\section{Procedure and Protocol}

A transradial artery approach using a 6Fr arterial sheath was routinely used for treatment of AMI unless the Allen's test was positive for both hands. A 6Fr Kimny Miniradial guiding catheter (Boston Scientific, Scimed, Inc, Maple Grove, MN, USA) was used for diagnosis and primary PCI. Immediately after coronary angioplasty, left ventriculograms were recorded in the $30^{\circ}$ right anterior oblique and $60^{\circ}$ left anterior oblique views.
At the beginning of this study the tirofiban loading dose $(20 \mu \mathrm{g} / \mathrm{kg})$ was administered to patients on presentation in the emergency room, followed by a maintenance infusion of $0.15 \mu \mathrm{g} \cdot \mathrm{kg}^{-1} \cdot \mathrm{min}^{-1}$ for $18-24 \mathrm{~h}$. However, tirofiban therapy was subsequently withheld because it was found not to provide any additional benefit to AMI patients who underwent primary $\mathrm{PCI}^{26}$ Therefore; only 49 (18.4\%) patients received tirofiban therapy. From May 2002, the PercuSurge GuardWire $^{\mathrm{TM}}$ device (Medtronic AVE) was used. Enrollment and exclusion criteria and the procedure of using PercuSurge have been previously described in detail.27

Clopidogrel $(300 \mathrm{mg}$ loading dose before stenting then $75 \mathrm{mg} /$ day) was given to patients who underwent primary stenting. Aspirin (100 mg orally daily) was given indefinitely to each patient. Other drugs commonly prescribed were angiotensin-converting enzyme inhibitors (ACEI), $\beta$ blockers, isonitrate and diuretics.

\section{Blood Sampling and Laboratory Investigations}

Blood samples were obtained from the healthy volunteers during healthy clinic examination, and from the atrisk control subjects in the outpatient department. Venous blood was withdrawn from the antecubital vein into EDTA tubes. After centrifugation, aliquots of the samples were stored at $-80^{\circ} \mathrm{C}$ before assay for IL-18. White blood cell (WBC) counts and biochemical measurements were done using standard laboratory methods.

Plasma IL-18 levels were measured by duplicate determination with a commercially available ELISA method (B $\& \mathrm{D}$; analytical range $5-5,000 \mathrm{pg} / \mathrm{ml})$. The intra-individual variability was assessed in the patients and both control groups. The mean intra-assay coefficients of variance were all less than $4.0 \%$. The levels of high-sensitivity C-reactive protein (hs-CRP) were measured by immunonephelometry using the $\mathrm{BN}^{\mathrm{TM}}$ system (Dade Behring Inc, Newark, DE, USA; lower detection limit $<0.15 \mathrm{mg} / \mathrm{L})$. The intra-individual variability was assessed in the 3 groups and the mean intra-assay coefficients of variance were $2.86 \%, 2.77 \%$, and $2.81 \%$, respectively.

\section{Definitions and Data Collection}

AMI was defined as the presence of typical chest pain for more than $30 \mathrm{~min}$ with ST-segment elevation $>1 \mathrm{~mm}$ in 2 or 
Table 2 Comparison of Baseline Characteristics, Laboratory Findings, Angiographic Results, and 30-Day Clinical Outcomes of Patients With High and Low IL-18 Levels Following Acute Myocardial Infarction

\begin{tabular}{|c|c|c|c|}
\hline & $\begin{array}{c}\text { High IL-18 level } \\
\quad(n=68)\end{array}$ & $\begin{array}{l}\text { Low IL-18 level } \\
\quad(n=199)\end{array}$ & $p$ value* \\
\hline Age (years) (mean $\pm S D)$ & $63.1 \pm 12.8$ & $59.3 \pm 12.0$ & 0.026 \\
\hline Female gender & $23.5 \%(16)$ & $18.1 \%(36)$ & 0.328 \\
\hline Hypertension & $55.9 \%(38)$ & $52.8 \%(105)$ & 0.656 \\
\hline Diabetes mellitus & $39.7 \%(27)$ & $29.2 \%(58)$ & 0.107 \\
\hline Current smoking & $52.9 \%(36)$ & $39.2 \%(78)$ & 0.048 \\
\hline Hypercholesterolemia & $42.7 \%(29)$ & $47.2 \%(94)$ & 0.512 \\
\hline Previous myocardial infarction & $10.3 \%(7)$ & $6.0 \%(12)$ & 0.276 \\
\hline Previous stroke & $8.8 \%(6)$ & $8.0 \%(16)$ & 0.839 \\
\hline WBC counts $\left(\times 10^{3} / \mathrm{ml}\right)$ & $11.6 \pm 4.6$ & $9.7 \pm 2.8$ & $<0.0001$ \\
\hline$h s-C R P(m g / L)$ & $13.1 \pm 23.0$ & $7.6 \pm 19.3$ & 0.030 \\
\hline$I L-18(\mathrm{pg} / \mathrm{ml})$ & $1,103 \pm 705$ & $292 \pm 122$ & $<0.0001$ \\
\hline Peak level of $C K-M B(U / L)$ & $667 \pm 525$ & $299 \pm 259$ & $<0.0001$ \\
\hline Anterior wall infarction & $66.2 \%(45)$ & $46.2 \%(92)$ & 0.005 \\
\hline Cardiogenic shock & $39.7 \%(27)$ & $7.5 \%(15)$ & $<0.0001$ \\
\hline Advanced $C H F(\geq N Y H A F c 3)$ & $67.6 \%(46)$ & $7.5 \%(15)$ & $<0.0001$ \\
\hline Multivessel disease & $69.1 \%(47)$ & $42.2 \%(84)$ & 0.0001 \\
\hline Pre-PCI TIMI flow grade $(\geq 2)$ & $13.2 \%(9)$ & $26.1 \%(52)$ & 0.030 \\
\hline Mean reperfusion time ( $\mathrm{min}$ ) & $326 \pm 164$ & $297 \pm 139$ & 0.240 \\
\hline Stenting & $84.9 \%(56)$ & $80.9 \%(161)$ & 0.612 \\
\hline PercuSurge GuardWire use & $39.7 \%(27)$ & $42.7 \%(85)$ & 0.664 \\
\hline Tirofiban & $11.8 \%(8)$ & $15.6 \%(31)$ & 0.442 \\
\hline Successful reperfusion & $77.9 \%(53)$ & $94.5 \%(188)$ & $<0.0001$ \\
\hline $\operatorname{LVEF}(\%)$ & $47.7 \pm 10.8$ & $59.6 \pm 11.7$ & $<0.0001$ \\
\hline 30-day mortality & $33.8 \%(23)$ & $1.0 \%(2)$ & $<0.0001$ \\
\hline
\end{tabular}

Data are mean value $\pm S D$ or $\%$ (no.) of patients.

CK, creatine kinase; CHF, congestive heart failure; NYHA Fc, New York Heart Association functional class; PCI, percutaneous coronary intervention; TIMI, Thrombolysis in Myocardial Infarction; LVEF, left ventricular ejection fraction. Other abbreviations see in Table 1.

*Continuous data analyzed by Wilcoxon's rank sum test, and categorical data analyzed by chi-square test or Fisher's exact test. ${ }^{\dagger} \mathrm{IL}-18 \mathrm{level} \geq 560 \mathrm{pg} / \mathrm{ml}$.

IL-18 level $<560 \mathrm{pg} / \mathrm{ml}$.

more consecutive precordial or inferior leads. Unsuccessful reperfusion was defined as failure to achieve normal blood flow after PCI ( $\leq$ Thrombolysis in Myocardial Infarction (TIMI)-2 flow) of the infarct-related artery. Reperfusion time was defined as the time from chest pain onset to the first balloon inflation. Detailed in-hospital and follow-up data, including age, sex, coronary risk factors, serial MB fraction of creatine kinase (CK-MB) levels, WBC counts, platelet counts, creatinine level, body temperature, Killip score on admission, severity of congestive heart failure (CHF), angiographic findings and number of diseased vessels, were collected prospectively and entered into a computerized database.

\section{Endpoints and Statistical Analysis}

The study endpoint was the 30-day composite occurrence of major adverse clinical events (MACE), including advanced CHF (defined as New York Heart Association functional class $\geq 3$ ) or 30 -day death. The baseline variables were used for univariate analysis. All of the univariate significant factors were further used for multiple stepwise logistic regression analysis.

Data are expressed as mean \pm SD. Categorical variables were compared using chi-square or Fischer's exact test. Continuous variables between 2 groups were analyzed by Wilcoxon's rank sum test. Continuous variables among 3 groups were compared using the Kruskal-Wallis test, followed by posthoc multiple comparison procedure with the Wilcoxon's rank sum test and Bonferroni's correction. Discriminate analysis was used to find the cut-off value of IL-18 that was the most significant with good sensitivity and specificity for predicting 30-day MACE. Statistical analysis was performed using SAS statistical software for Windows version 8.2 (SAS Institute, Cary, NC, USA). A value of $p<0.05$ was considered statistically significant.

\section{Results}

Baseline Characteristics of AMI Patients, At-Risk Control Subjects and Healthy Control Subjects (Table 1)

There was neither significant difference among the 3 groups for age and gender nor between AMI patients and the at-risk control subjects for coronary artery disease risk factors. However, the hs-CRP level, WBC counts and IL-18 level were significantly higher in AMI patients than in the at-risk control and healthy control subjects. Additionally, the hs-CRP level was significantly higher in the at-risk control subjects than in the healthy control subjects.

Baseline Characteristics, Laboratory Findings, Angiographic Results, and 30-Day Clinical Outcomes for AMI Patients (Table 2)

The plasma IL-18 level $\geq 560 \mathrm{pg} / \mathrm{ml}$ was the most powerful cut-off value identified using the discriminating test for predicting 30-day MACE, with a sensitivity of $84.7 \%$ and a specificity of $90.4 \%$. Thus, patients with a plasma IL-18 level $\geq 560 \mathrm{pg} / \mathrm{ml}$ were classified into the high level group (Group 1) and those with a plasma level $<560 \mathrm{pg} / \mathrm{ml}$ were assigned to the low level group (Group2). Except for age and current smoking, these 2 groups were similar in gender, cardiovascular risk factors, previous MI, previous stroke, incidence of tirofiban therapy and mean reperfusion time. 
Table 3 Univariate Stepwise Logistic Regression Analysis of Variables Relevant to 30-Day Major Adverse Clinical Outcomes

\begin{tabular}{|c|c|c|c|}
\hline & $O R$ & $95 \% C I$ & $p$ value \\
\hline Age (years) $(\geq 70 v s<70)$ & 2.97 & $1.63-5.40$ & 0.0004 \\
\hline Female vs male & 1.84 & $0.95-3.55$ & 0.068 \\
\hline With vs without hypertension & 0.97 & $0.56-1.70$ & 0.921 \\
\hline With vs without diabetes mellitus & 2.03 & $1.14-3.61$ & 0.016 \\
\hline With vs without current smoking & 1.07 & $0.61-1.87$ & 0.814 \\
\hline With vs without hypercholesterolemia & 0.82 & $0.47-1.44$ & 0.494 \\
\hline$I L-18(\geq 560$ vs $<560) *(\mathrm{pg} / \mathrm{ml})$ & 27.61 & $13.35-57.09$ & $<0.0001$ \\
\hline Peak level of $C K-M B(U / L)$ & 1.00 & $0.99-1.00$ & $<0.0001$ \\
\hline hs-CRP level $(\mathrm{mg} / \mathrm{L})$ & 0.99 & $0.98-1.01$ & 0.229 \\
\hline WBC counts $\left(\times 10^{3} / \mathrm{ml}\right)$ & 0.89 & $0.83-0.97$ & 0.004 \\
\hline With vs without anterior wall infarction & 2.54 & $1.41-4.57$ & 0.002 \\
\hline With vs without cardiogenic shock & 17.98 & $8.09-39.94$ & $<0.0001$ \\
\hline With vs without multi-vessel disease & 2.61 & $1.46-4.69$ & 0.001 \\
\hline Mean reperfusion (>240 vs $\leq 240 \mathrm{~min})$ & 1.08 & $0.61-1.91$ & 0.785 \\
\hline Post-procedure TIMI-flow (3 vs $\leq 2)$ & 0.28 & $0.12-0.65$ & 0.003 \\
\hline $\operatorname{LVEF}(\%)(<50$ vs $\geq 50)$ & 12.59 & $6.57-24.14$ & $<0.0001$ \\
\hline
\end{tabular}

OR, odds ratio; $C I$, confidence interval. Other abbreviations see in Tables 1,2.

*Percentage of IL-18 level $\geq 560 \mathrm{pg} / \mathrm{ml}$ found to be the most powerful cut-off value using the discriminating test for predicting 30 day composite major adverse clinical outcomes (defined as advanced congestive heart failure $\geq$ class 3 or 30-day death).

Table 4 Multiple Stepwise Logistic Regression Analysis of Independent Predictors for 30-Day Major Adverse Clinical Outcomes

\begin{tabular}{lccc}
\hline \hline & OR & $95 \%$ CI & p value \\
\hline$I L-18 \geq 560(\mathrm{pg} / \mathrm{ml})$ & 12.74 & $5.28-30.75$ & $<0.0001$ \\
LVEF $<50 \%$ & 6.60 & $2.67-16.33$ & $<0.0001$ \\
Age $(\geq 70$ years $)$ & 3.47 & $1.33-9.03$ & 0.011 \\
Cardiogenic shock & 12.29 & $3.86-39.13$ & $<0.0001$ \\
\hline
\end{tabular}

Abbreviations see in Tables 1-3.

Table 5 Multiple Stepwise Logistic Regression Analysis of Independent Predictors for 30-Day Mortality

\begin{tabular}{lccc}
\hline \hline & OR & $95 \% C I$ & $p$ value \\
\hline$I L-18 \geq 560(\mathrm{pg} / \mathrm{ml})$ & 33.0 & $6.95-156.9$ & $<0.0001$ \\
Cardiogenic shock & 6.41 & $2.17-18.95$ & 0.001
\end{tabular}

Abbreviations see in Tables 1-3.

However, the WBC counts, plasma levels of hs-CRP and IL-18, and peak level of CK-MB were substantially higher in Group 1 than in Group 2 patients. Furthermore, the incidence of cardiogenic shock and advanced CHF were remarkably higher in Group 1 than in Group 2 patients. There was no significant difference in the frequency of using the PercuSurge device or stenting between Group 1 and Group 2 patients. However, the incidence of anterior wall infarction and multivessel disease were significantly higher in Group 1 than in Group2, whereas left ventricular ejection fraction (LVEF), pre-PCI TIMI flow $\geq 2$ in the infarct-related artery and successful reperfusion were markedly lower in Group 1 patients than in Group 2 patients. Moreover, Group 1 patients had a noticeably higher 30-day mortality rate than Group 2 patients.

Correlation analysis demonstrated that there was a significant direct relationship between the IL-18 level and CK-MB peak level $(\mathrm{r}=0.469, \mathrm{p}<0.0001)$.

Determinants of 30-Day Composite MACE

Table 3 presents the results of univariate analysis for factors associated with composite 30-day MACE. The most significant factors were high IL-18 level $(\geq 560 \mathrm{pg} / \mathrm{ml})$, peak CK-MB level, cardiogenic shock, and LVEF $\leq 50 \%$.
Age $\geq 70$ years, diabetes mellitus, WBC count, multivessel disease and anterior wall MI were significantly related to an increased incidence of 30-day MACE, whereas successful reperfusion was associated with a decreased 30-day MACE.

Multiple stepwise logistic regression analysis (Table4) of all significant univariate factors showed that IL-18 level, LVEF $<50 \%$, and cardiogenic shock were the strongest independent predictors of 30-day MACE. Older age $(\geq 70$ years) was also independently predictive of 30-day MACE. Multiple stepwise logistic regression analysis (Table 5) of all significant univariate factors showed that IL-18 level was the most significant and independent factor associated with 30-day mortality. Although less powerful than the IL18 level, cardiogenic shock was also independently predictive of 30-day mortality.

\section{Discussion}

The present study, in which the circulating levels of inflammatory biomarkers and clinical relevant variables were examined in patients with STEMI undergoing primary PCI, produced several striking clinical implications. First, patients with high circulating IL-18 level had a 
30-day morality rate $>33$-fold higher than that of patients with a low circulating IL-18 level. Second, there was a strong independent association between increasing IL-18 level and 30-day mortality and MACE. Third, the results confirmed those of previous observation studies ${ }^{28-31}$ in which cardiogenic shock, low LVEF and older age were predictive of 30-day MACE in AMI patients. The present study, therefore, further strengthened the suggestion that the impact of these 3 clinically relevant factors on MACE was independent of the use of primary PCI.

Interleukin-18 acts directly as a proinflammatory cytokine ${ }^{21}$ by inducing IL- 13, IL- $8,16,17$ and the expression of adhesion molecules? ${ }^{2}$ IL-18 is also able to stimulate the production of granulocyte-macrophage colony-stimulating factor, tumor necrotic factor $a$, and inducible nitric oxide synthetase by mononuclear and mesenchymal cells? ${ }^{21}$ Surprisingly, in view of the potent inflammatory activities of IL-18, 20,22-24 data addressing the prognostic value of the circulating level of IL-18 in STEMI patients undergoing primary PCI are not available. To the best of our knowledge, the present study is the largest and first cohort study to evaluate the impact of the circulating levels of IL-18 in such patients. One important finding of this study, consistent with that of a previous study, 25 is that the plasma level of IL-18 is substantially higher in AMI patients than in either at-risk or normal control subjects. We remain uncertain about when, how fast and the mechanisms by which IL-18 is released into the circulation following AMI. However, compared with the baseline IL-18 level of the present at-risk control subjects, and based on previous observation studies, $9,20,25$ we suggest that the level of circulating IL-18 is rapidly and markedly increased immediately following AMI. A previous study found that the plasma IL18 level elevated quickly after severe myocardial ischemia, 33 which supports our suggestion. Additionally, previous studies have clearly shown that an acute elevation of inflammatory mediators occurs following $\mathrm{ACS}^{2,4,25,33}$ and another ${ }^{9}$ found that AMI induced cardiac release of cytokines and inflammatory responses. Moreover, an experimental study 10 demonstrated that cytokine gene expression was induced rapidly following AMI. Accordingly, we suggest that the rapidly increased circulating level of IL-18 in the present patients was mainly a result of myocardial injury following AMI, which in turn mediated an acute inflammatory response.

Convincing data support that IL-18 directly participates in vascular inflammation; $6,22,23$ however, the contribution of IL-18 to myocardial damage in the clinical setting of AMI is currently unclear. Another important finding in this investigation was that patients with a higher circulating level of IL-18 had a significantly lower pre-interventional TIMI flow (grade $\geq 2$ ) and less successful reperfusion than those patients with a lower circulating level of IL-18. Additionally, the circulating level of IL-18 strongly correlated with peak CK-MB levels, low LVEF and high incidences of advanced CHF, cardiogenic shock and anterior wall MI. Moreover, the hs-CRP level was significantly higher in patients with a high IL-18 level than in those with a low IL-18 level. Accordingly, we suggest that IL-18 directly participates in damaging the integrity of the microvasculature, microvascular reperfusion injury and myocardial damage through the inflammatory response. Recent studies have demonstrated that a robust inflammatory response is an integral component of the response to tissue injury and plays a particularly active role after AMI ${ }^{13,34-36}$ Evidence also supports that rapidly and markedly increased circulat- ing levels of neurohormones or inflammatory cytokines, which in turn elicit overreactive responses systemically, are harmful to AMI patients9,37,38 Additionally, in the acute phase of AMI, circulating levels of CRP, an index of inflammation, are likely to predominantly reflect the inflammatory response to myocardial necrosis rather than by chronic vascular inflammation. ${ }^{34-36}$ Moreover, an association between increased circulating cytokines and microvascular reperfusion injury has been identified.,39 Furthermore, cytokines originating from the myocardium or infiltrating inflammatory cells contribute to the raised CRP concentrations observed in patients with AMI 36 Accordingly, our suggestion, based on our findings, is further supported by the findings of these studies?,13,34-36,39

The most important finding in the present study is that an increased circulating level of IL-18 has been identified as a major independent predictor of 30-MACE and mortality. Recently, inflammatory cytokines were further identified as predictive of untoward clinical outcomes!1 Therefore, our finding strengthens those of another recent study ${ }^{11}$ and encourages the use of the circulating level of IL-18 as a predictor of clinical outcomes in patients following AMI.

\section{Study Limitations}

First, without serial measurement of circulating IL-18 levels, we could not provide information regarding how early the circulating IL-18 elevated and how long the elevation of IL-18 persisted. However, previous studies have demonstrated that the IL-18 level is highly dynamic following AMI, with a marked increase in the early phase of AMI and correlation with myocardial injury? 25,33 Second, the effects of circulating IL-18 on long-term clinical outcomes were not part of the protocol, so these relationships did not extended beyond the 30-day clinical outcome endpoint.

\section{Conclusion}

The present study demonstrated that the circulating level of IL-18 was substantially increased in patients with STEMI. We suggest its use as a marker of the acute inflammatory process and an index of myocardial necrosis. Additionally, a higher circulating IL-18 level $(\geq 560 \mathrm{pg} / \mathrm{ml})$ on admission is strongly associated with increased 30-day MACE and death. These findings highlight the use of the circulating IL-18 level for risk stratification of patients with AMI.

\section{References}

1. Ross R. Atherosclerosis: An inflammatory disease. $N$ Engl J Med 1999; 340: 115-126.

2. Yip HK, Sun CK, Chang LT, Wu CJ. Strong correlation between serum levels of inflammatory mediators and their distribution in infarct-related coronary artery. Circ J 2006; 70: 838-845.

3. Falk E, Shah PK, Fuster V. Coronary plaque disruption. Circulation 1995; 92: 657-761.

4. Burke AP, Tracy RP, Kologie F, Malcom GT, Zieske A, Kutys R, et al. Elevated C-reactive protein values and atherosclerosis in sudden coronary death: Association with different pathologies. Circulation 2002; 105: 2019-2023.

5. Lee RT, Libby P. The unstable atheroma. Arterioscler Thromb Vasc Biol 1997; 17: 1859-1867.

6. Mallat Z, Corbaz A, Scoazec A, Besnard S, Leseche G, Chvatchko $\mathrm{Y}$, et al. Expression of interleukin-18 in human atherosclerotic plaques and relation to plaque instability. Circulation 2001; 104: 1598-1603.

7. Libby P, Ridker PM, Maseri A. Inflammation and atherosclerosis. Circulation 2002; 105: 1135-1143.

8. Maier W, Altwegg LA, Corti R, Gay S, Hersberger M, Maly FE, et al. Inflammatory markers at the site of rupture plaque in acute myocardial infarction. Circulation 2005; 111: $1355-1361$. 
9. Neumann FJ, Ott I, Gawaz M, Richardt G, Holzapfel H, Jochum M, et al. Cardiac release of cytokines and inflammatory response in acute myocardial infarction. Circulation 1995; 92: 748-755.

10. Ono K, Matsumori A, Shioi T, Furukawa Y, Sasayama S. Cytokine gene expression after myocardial infarction in rat hearts: Possible implication in left ventricular remodeling. Circulation 1998; 98: 149-156.

11. Valgimigli M, Ceconi C, Malagutti P, Merli E, Soukhomovskaia O, Francolini G, et al. Tumor necrotic factor-alpha receptor 1 is a major predictor of mortality and new-onset heart failure in patients with acute myocardial infarction. Circulation 2005; 111: $863-870$.

12. Cusack MR, Marber MS, Lambiase PD, Bucknall CA, Redwood SR. Systemic inflammation in unstable angina is the result of myocardial necrosis. J Am Coll Cardiol 2002; 39: 1917-1923.

13. Ridker PM, Rifai N, Stampfer MJ, Hennekens CH. Plasma concentration of interleukin- 6 and risk of future myocardial infarction among apparently healthy men. Circulation 2000; 101: 1767-1772.

14. Blankenberg S, Luc G, Ducimetiere P, Arveiler D, Ferrieres J, Amouyel P, et al. Interleukin-18 and risk of coronary heart disease in European men: The Prospective Epidemiological Study of Myocardial Infarction (PRIME). Circulation 2003; 108: 2453-2459.

15. Ghayur T, Banerjee S, Hugunin M, Butler D, Herzog L, Carter A, et al. Caspase-1 processes IFN-gamma-inducing factor and regulate LPS-induced IFN-gamma production. Nature 1997; 368: 619-623.

16. Gu Y, Kuida K, Tsutsui H, Ku G, Hsiao K, Fleming MA, et al. Activation of interferon-gamma inducing factor medicated by interleukin-1 beta converting enzyme. Science 1997; 275: 206-209.

17. Okamura H, Tsutsi H, Komatsu T, Yutsudo M, Hakura A, Tanimoto $\mathrm{T}$, et al. Cloning of a new cytokine that induces IFN-gamma production by T cells. Nature 1995; 378: $88-89$.

18. Libby P. Molecular bases of the acute coronary syndromes. Circulation 1995; 91: 2844-2850.

19. Gupta S, Pablo AM, Jiang X, Wang N, Tall AR, Schindler C. IFNgamma potentiates atherosclerosis in ApoE knock-out mice. J Clin Invest 1997; 99: 2752-2761.

20. Okamura H, Tsutsui H, Kashiwamura S, Yoshimoto T, Nakanishi K. Interleukin-18: A novel cytokine that augments both innate and acquired immunity. Adv Immunol 1998; 70: 281-312.

21. Gracie JA, Robertson SE, McInnes IB. Interleukin-18. J Leukoc Biol 2003; 73: 213-224.

22. Mallat Z, Corbaz A, Scoazec A, Besnard S, Lesèche g, Chvatchko Y, et al. Interleukin-18/interleukin-18 binding protein signaling modulates atherosclerotic lesion development and stability. Circ Res 2001; 89: $\mathrm{E} 41-\mathrm{E} 45$.

23. Whitman SC, Ravisankar P, Daugherty A. Interleukin-18 enhances atherosclerosis in apolipoprotein $\mathrm{E}(-/-)$ mice through release of interferon-gamma. Circ Res 2002; 90: E34-E38.

24. Tiret L, Godefroy T, Lubos E, Nicaud V, Tregouet DA, Barbaux S, et al. Genetic analysis of the interleukin-18 system highlights the role of the interleukin-18 gene in cardiovascular disease. Circulation 2005; 112: $643-650$.

25. Seta Y, Kanda T, Tanaka T, Arai M, Sekiguchi K, Yokoyama T, et al. Interleukin 18 in acute myocardial infarction. Heart 2000; 84: 668669.

26. Yip HK, Wu CJ, Chang HW, Hsieh YK, Fang CY, Chen MC, et al. Impact of tirofiban on angiographic morphologic features of highburden thrombus formation during direct percutaneous coronary intervention and short-term outcomes. Chest 2003; 124: 962-968.

27. Yip HK, Wu CJ, Chang HW, Fang CY, Yang CH, Chen SM, et al. Effect of the PercuSurge GuardWire Device on the integrity of microvasculature and clinical outcomes during primary transradial coronary intervention in acute myocardial infarction. Am J Cardiol 2003; 92: $1331-1335$.

28. Goldberg RJ, Gore JM, Alpert JS, Osganian V, de Groot J, Bade J, et al. Cardiogenic shock after acute myocardial infarction: Incidence and mortality from a community-wide perspective, 1875-1988. N Engl J Med 1991; 325: 1117-1122.

29. Yip HK, Wu CJ, Chang HW, Hang CL, Fang CY, Hsieh YK, et al. Comparison of primary angioplasty and conservative treatment on short- and long-term outcome in octogenarian or older patients with acute myocardial infarction. Jpn Heart J 2002; 43: $463-474$.

30. Yip HK, Wu CJ, Chang HW, Chen MC, Hang CL, Fang CY, et al. Comparison of impact of primary percutaneous transluminal coronary angioplasty and primary stenting on short-term mortality in patients with cardiogenic shock and elevation of prognostic determinants. Am J Cardiol 2001; 78: 1184-1188.

31. Wu CJ, Chang HW, Hung WC, Yang CH, Chen YH, Su CY, et al. Nterminal pro-brain natriuretic peptide is a biomarker of congestive heart failure and predictive of 30-day untoward clinical outcomes in patients with acute myocardial infarction undergoing primary percutaneous coronary intervention. Circ J 2006; 70: 163-168.

32. Puren AJ, Fantuzzi G, Gu Y, Su MSS, Dinarello CA. Interleukin-18 (IFNgamma-inducing factor) induces IL-8 and IL-1 beta via TNF alpha production from non-CD14+ human blood mononuclear cells. Clin Invest 1998; 101: 711-721.

33. Kawasaki D, Tsujino T, Morimoto S, Masai M, Masutani M, Ohyanagi $\mathrm{M}$, et al. Plasama interleukin-18 concentration: A novel marker of myocardial ischemia rather than necrosis. Coron Artery Dis 2005; 16: 437-441.

34. Suleiman M, Khatib R, Agmon Y, Mahamid R, Boulos M, Kapeliovich M, et al. Early inflammation and risk of long-term development of heart failure and mortality in survivors of acute myocardial infarction: Predictive role of C-reactive protein. $\mathrm{J} \mathrm{Am}$ Coll Cardiol 2006; 47: 962-968.

35. James S, Oldgren J, Lindback J, Johnston N, Siegbahn A, Wallentin L. An acute inflammation induced by myocardial damage is superimposed on chronic inflammation in unstable coronary artery disease. Am Heart J 2005; 149: 619-626.

36. Suleiman M, Aronson D, Reisner SA, Kapeliovich MR, Markiewicz W, Levy Y, et al. Admission C-reactive protein levels and 30-day mortality in patients with acute myocardial infarction. Am J Med 2003; 115: 695-701.

37. Singh RB, Pella D, Neki NS, Chandel JP, Rastogi S, Mori H, et al. Mechanisms of acute myocardial infarction study (MAMIS). Biomed Pharmacother 2004; 58: S111-S115.

38. Yip HK, Wu CJ, Chang HW, Yang CH, Yu TH, Chen YH, et al. Prognostic value of circulating levels of endothelin-1 in patients after acute myocardial infarction undergoing primary coronary angioplasty. Chest 2005; 127: $1491-1497$.

39. Kukielka GL, Smith W, Manning AM, Youker KA, Michael LH, Entman ML. Induction of interleukin-6 synthesis in myocardium: Potential role in postreperfusion inflammatory injury. Circulation 1995; 92: 1866-1872. 